\title{
Predominant Coaching Leadership Behaviors of High School Head Basketball Coaches: A Pilot Study
}

\author{
Eddie T. C. Lam ${ }^{1 *}(\mathbb{D}$, Stephanie S. J. Drcar², Xuan Song3 \\ ${ }^{1}$ Department of Health \& Human Performance, Cleveland State University, Cleveland, Ohio, USA \\ ${ }^{2}$ Department of Counseling, Administration, Supervision \& Adult Learning, Cleveland State University, Cleveland, Ohio, USA \\ ${ }^{3}$ Doctoral Studies, Cleveland State University, Cleveland, Ohio, USA \\ Email: ^t.lam@csuohio.edu
}

How to cite this paper: Lam, E. T. C., Drcar, S. S. J., \& Song, X. (2021). Predominant Coaching Leadership Behaviors of High School Head Basketball Coaches: A Pilot Study. Open Journal of Social Sciences, 9, 219-243.

https://doi.org/10.4236/jss.2021.911019

Received: September 17, 2021

Accepted: November 26, 2021

Published: November 29, 2021

Copyright $\odot 2021$ by author(s) and Scientific Research Publishing Inc. This work is licensed under the Creative Commons Attribution International License (CC BY 4.0).

http://creativecommons.org/licenses/by/4.0/

\begin{abstract}
Coaching leadership in sport was important because the coach-athlete relationship was considered as a crucial factor in the sport setting. Though leadership theories have been developed for a few decades, research topics related to leadership behaviors in high school settings are understudied. The purpose of the study was to examine the coaching leadership behaviors of high school head basketball coaches in Hong Kong utilizing the Leadership Scale for Sports. One hundred and twelve basketball coaches were invited to participate in the study: 56 coaches from the winning teams and another 56 coaches from the losing teams. Mixed-design $2 \times 5$ ANOVA indicated there was significant $(p<.001)$ main effect for the coaching behaviors. Both the top-ranking and low-ranking head basketball coaches exhibited significantly $(p<.001)$ higher level of Teaching and Instruction as well as Positive Feedback than Social Support, Democratic Behavior, and Autocratic Behavior. The mean scores as determined by the five dimensions of the LSS were in the following descending order: Positive Feedback, Training and Instruction, Social Support, Democratic Behavior, and Autocratic Behavior. The importance and application of these five coaching behaviors were discussed in detail.
\end{abstract}

\section{Keywords}

Positive Feedback, Training and Instruction, Social Support, Democratic Behavior, Autocratic Behavior

\section{Introduction}

Effective coaching has long been a subject of discussion among coaches, athletes, 
and educators. Studies related to sport leadership either concentrated on the characteristics of the personality of the coaches (e.g., Cassidy et al., 2008; Gama et al., 2019; Vallée \& Bloom, 2005), or focused on a situational approach which hypothesized that different leadership behaviors were required for different settings (e.g., Horn et al., 2011; Lyle, 2005; Mwai, 2011; Smith, 2006; Sullivan et al., 2012; Turman, 2003). A typical example of understanding of coaches' leadership behaviors was a study by Bloom and Salmela (2000) in which they not only investigated leadership skills of coaches based on the needs of the athlete and the situation, but also elicited the similar attributes on coaching preferences, goals, and beliefs. The importance of developing coaches' leadership styles in sport was also studied by many scholars in a variety of aspects. Chase (2010) argued that coaching education and leadership training should consider helping them to develop a growth mindset about their leadership abilities rather than attempting to identify the elusive formula on how to be a great leader (p. 297). Lee and Chelladurai (2018) found that coaches as leaders should both focus on the quality evolvement and the development of emotional intelligence. Some other researches (e.g., Johnson et al., 2011) studied the relationship between the coach's leadership behavior and the reactions of athletes as a crucial and important factor in the sport setting both in the training process and during competitions.

A consistent finding in most studies revealed that athlete satisfaction with their coaches is closely related to their active responses to the presence of perceived training and instruction, social support, positive feedback, and sometimes democratic behavior (Chelladurai et al., 1989; Dwyer \& Fischer, 1990; Weiss \& Friedrichs, 1986). Kao et al. (2015) noted that athletes' satisfaction can be a product of athletic director if a proactive behavior from the coaches was imposed. This study demonstrated that the congruence between perceived and required (e.g., as defined by athletic directors) positive feedback was connected with athlete satisfaction, thus the cultural context for coaching should be considered. This outcome was supported by the study of Prati and Pietrantoni (2013) which indicated that there was a correlation between the social support dimension of the value congruence and the training and instruction dimension of the perceptual congruence. Another study for preferred coaching leadership behavior in the cultural context of the sport and athletes was conducted by Riemer (2007), who summarized the various ways in which culture may serve as an impactful predictor of leadership preferences including sport type (e.g., team or individual sport, Western or Eastern sport, levels of task variability and dependence) and the competitive nature of the sport (e.g., students versus elite/competitive athletes). Riemer's finding responded the prior study by Chelladurai et al. (1987) regarding differences between preferences in Eastern versus Western sports. Chelladurai et al. compared Japanese students and Canadian students in Western sports and found that the cultural background of the students and the sport type did significantly impact leadership preferences (e.g., Japanese students 
in Eastern sports preferred more distant and authoritarian leadership compared to Canadian and Japanese students within Western sports). Horn (2008) initiated a working model of coaching effectiveness, which is generally consistent with Chelladurai's (1978) model of leadership effectiveness in sport but specified three assumptions: 1) antecedent factors (i.e., sociocultural context, organizational climate, and coaches' personal characteristics)influence coaches' behaviors indirectly through coaches' expectancies, beliefs, and goals, 2) coaches' behaviors directly influence athletes' evaluations of their coaches' behaviors and team performance, and 3) the effectiveness of coaches' behaviors is influenced by situational factors and athletes' individual differences (Sullivan et al., 2012: p. 123). This model sets up an important foundation for researches on inquiry into the impact of contextual of coaching behaviors and its impact on athletic performance. Influenced by the multidimensional perspective, Ryska (2009) expanded leadership studies of coachers in sport from the bilateral aspect of dispositional, situational and administrative factors on the performance of athletes to a multivariate stage, and extended variables to a wider scale like team motivation, positive feedback, and group dynamics (Weinberg \& Gould, 2015).

Although the above literatures related to the Multidimensional leadership have spanned a variety of contexts and provided valuable insights into common coaching behavior. For example, the multidimensional model of sport leadership provides support for an interactional approach to studying leadership in sport as findings indicate that situational factors and characteristics of the leader do interact (Horn, 2002). However, criticism to the Multidimensional Model of Leadership (MML) model suggested a lack of comprehensive research that has examined correlational rather than causal links in the model. There are still lacking experimental or quasi-experimental research, which could clarify the specific relationships that exist within these assumptions and causal relationships between coaching behaviors and outcomes of athlete satisfaction and performance. Chase (2010) pointed out the limitations of this model by saying that "the multidimensional model of sport leadership does not address perceptions about one's ability to lead and how abilities to lead originate" (p. 300). Meanwhile, understanding the impact of coaching behaviors on the performance of athletes' outcomes in a very intersectional setting remains understudied. Therefore, it is necessary to investigate the predominant coaching leadership behaviors from a multitude perspective and to seek its causation on athletic performance. By choosing a model of MML in sport as its theoretical framework, this study examined the predominant coaching leadership behaviors of high-ranking and low-ranking high school head basketball coaches in Hong Kong and tried to answer the following research questions: a) "Would there be differences in the coaching behaviors leadership behaviors between high-ranking and low-ranking high school head basketball coaches?" and b) "Would there be a preference of certain coaching leadership behaviors by the head basketball coaches as measured by the Leadership Scale for Sports?” (Chelladurai \& Saleh, 1980). 


\section{Literature Review}

The following section discusses the development of the MML and how the LSS was evolved from the MML to become a measurement tool for the leadership coaching behaviors of sports. Then the section moves on to sketch the most pertinent antecedents regarding the preferences of coaching behaviors and the relationship between coach leadership behavior and outcome performance as well as satisfaction of athletes.

\subsection{Multidimensional Model of Leadership in Sport}

In the light of viewing leadership in sports from a variety of aspects to reflect its multitude perspectives, Chelladurai and Saleh (1978) developed a five-dimensional description of the leadership styles for sports including autocratic, democratic, positive feedback, social support, and training and instruction believed to exist in athletics, this is the originality of MML. Chelladurai's $(1978,1990,1993,2001)$ MML represented a significant advancement in the study of coaching leadership given its use of the rich leadership literature while being directly relevant to sport settings. The central idea of Chelladurai's model is that "when the behaviors that the athletes prefer their coach to exhibit are congruent or consistent with both the coaching behaviors that the coach actually exhibits as well as the coaching behaviors that are required/desirable in that particular sport context, then maximum performance and athlete satisfaction can be achieved" (Horn et al., 2011: p. 191). The foundational premise of the MML is that congruence between preferred, required, and actual coach leadership behavior impacts two primary outcomes including athlete satisfaction and performance. In this vein, when actual coach behavior aligns with preferred and required coach behaviors, athlete performance and satisfaction would also increase. Chelladurai's MML model benefitted coaching researches as "it attributed coaches' success to more than great leadership skills; rather, to their capacity to display actual leadership behaviors that responded to a combination of demands from the environment, the players, and the coaches themselves" (Vallée \& Bloom, 2005: p. 180). However, criticism of the MML model suggested a lack of comprehensive research that has examined correlational, rather than causal, links in the proposed model. Chase (2010) pointed out the limitations of this model that the multidimensional model of sport leadership does not address perceptions about one's ability to lead and how abilities to lead originate (Chase, 2010: p. 300). Anyhow, this model provided successful coaches a tool to adjust themselves to immediate demands through incorporating the required and preferred behaviors into their actual behaviors (Riemer, 2007).

\subsection{Leadership Scale for Sports}

Based on MML model, Chelladurai and Saleh (1980) developed the LSS to measure the leadership styles used by coaches when directing their athletes. They used three surveys that measured athletes' preferences and perceptions of 
their coaches and leadership styles that coaches believed they used during interaction with their athletes, as a more accurate reflection of the coaching process. The LSS (Chelladurai \& Saleh, 1980) has supported research of the MML and has examined the tenets of the theory while also providing valuable information related to common coaching leadership behaviors across varied settings and athletes. The LSS measures five dimensions of coach leadership behavior in sport settings and those include: training and instruction, democratic behavior, autocratic behavior, social support, and positive feedback (Chelladurai \& Saleh, 1980). During the past two decades, many researchers have used the LSS to examine leadership in sports to identify athlete preferences and perceptions based on sport type (Chelladurai, 1984; Horne \& Carron, 1985), and culture (Chelladurai, 2001, 2007; Chelladurai et al., 1987). Literature on the MML, usually using the LSS, encompasses several areas: 1) leadership preferences depending on athlete and situational characteristics, 2) the relationship between leadership behaviors and outcomes of athlete satisfaction and performance, and finally 3 ) the congruence between leadership behaviors (e.g., actual, preferred, and required) and outcomes of athlete satisfaction and performance. The third area of scholarship has focused on the central tenet of the MML and support has been mixed for the congruence hypothesis when appropriate statistical methods are employed compared to past research on the topic (Andrew, 2009; Kao et al., 2015; Riemer \& Toon, 2001).

\subsection{Coaching Leadership Behavior Preferences}

The majority of research using the MML has been descriptive in nature and has consistently identified that athletes prefer training and instruction and positive feedback and least prefer autocratic behavior (Chelladurai, 1993; Chelladurai \& Riemer, 1998; Høigaard et al., 2008). Research on coaching leadership behavior preferences frequently examines antecedents such as athlete and situational characteristics. The current review of this literature will examine the most pertinent antecedents including athlete maturity and interdependent sports (versus independent sports) given that the current study examined high school basketball coaches.

Hersey and Blanchard (1982) noted that leaders must adapt their behavior based upon the maturity level of subordinates. Chelladurai and Carron (1983) defined athletic maturity using three factors: 1) competitive level of play, 2) years of experience in a sport, and 3) athlete age. Chelladurai and Carron (1983) generally found that as athletes mature they prefer greater levels of social support and lesser levels of positive feedback. Conversely, more recent research discovered that younger, less-experiences athletes preferred greater levels of social support and democratic behavior (Høigaard et al., 2008) and athletes of lesser ability preferred more positive feedback behavior (Riemer \& Toon, 2001). Høigaard et al. (2008) hypothesized that mature athletes may have a clearer understanding of their role and performance and therefore prefer less positive feed- 
back compared to their less-experienced counterparts.

Chelladurai (1978), in recognition of House's (1971) path-goal theory of leadership, identified the impact of task dependency and task variability on subordinate leadership preferences and proposed differences would exist between team and individual sports. The results from this line of inquiry have been mixed (Aleksic-Veljkovic et al., 2016; Beam et al., 2004; Chelladurai \& Saleh, 1978; LaForge et al., 2012; Lindauer, 2000; Pyun et al., 2010; Riemer \& Chelladurai, 1995; Terry, 1984; Terry \& Howe, 1984). For example, Terry (1984) discovered that team sport athletes preferred significantly more training and instruction, autocratic behavior, and positive feedback, but less democratic behavior and social support, than individual sport athletes. Meanwhile, Terry and Howe (1984) also concluded that athletes in independent sports preferred more democratic and less autocratic behavior than did the athletes in interdependent sports. On the contrary, Aleksic-Veljkovic et al. (2016) found no significant difference in the preference of democratic behavior or autocratic behavior between individual and team sports college athletes; whereas Lindauer (2000) unveiled that individual sport athletes (particularly track and field athletes) preferred a greater degree of democratic behavior than team sport athletes.

Lastly, another potential antecedent for preferred coaching leadership behavior is the cultural context of the sport and athletes. Riemer (2007: p. 66) summarized the various ways in which culture may serve as an impactful predictor of leadership preferences including sport type (e.g., team or individual sport, Western or Eastern sport, levels of task variability and dependence) and the competitive nature of the sport (e.g., students versus elite/competitive athletes). Regarding differences between preferences in Eastern versus Western sports, Chelladurai et al. (1987) found that the cultural background of the students and the sport type did significantly impact leadership preferences in that Japanese students in Western sports preferred more democratic decision making compared to Canadian students. Additionally, Japanese students in Eastern sports preferred more distant and authoritarian leadership compared to Canadian and Japanese students within Western sports. Additionally, Chelladurai et al. (1987) found that with Western sports, Japanese athletes preferred more social support and autocratic behavior compared to their Canadian counterparts who preferred more training and instruction. The literature is lacking more recent inquiry into the impact of cultural context on coaching behaviors and will benefit from expanded findings in this area.

\subsection{Coaching Leadership Behavior and Outcomes}

Within the realm of research focused on coach leadership behaviors and outcomes of athlete satisfaction and performance, the majority of the literature focuses upon athlete perceptions of coach leadership behaviors as opposed to coach perceptions of their own behavior. A consistent finding regarding the relationship between athlete perception of coach leadership behaviors and athlete 
satisfaction is that athlete satisfaction is positively related to the presence of perceived training and instruction, social support, positive feedback, and sometimes democratic behavior (Chelladurai et al., 1989; Dwyer \& Fischer, 1990; Weiss \& Friedrichs, 1986). Kao et al. (2015) highlighted the importance of the cultural context in their study of collegiate volleyball athletes and their coaches in Taiwan. They noted that Chinese culture emphasizes highly hierarchical relationships between leaders and team members and that the expectations of athletic directions will influence the required behavior of coaches, and therefore athlete satisfaction will also be a product of athletic director expectations in a Chinese cultural setting. Kao et al. (2015) found that congruence between perceived and required (e.g., as defined by athletic directors) positive feedback was connected with athlete satisfaction, thus supporting their hypothesis that the hierarchical structure in this cultural context should be considered.

Findings related to athlete perceptions of coach leadership behavior and performance outcomes are more varied. Some literature has found that higher social support (Weiss \& Friedrichs, 1986) and higher autocratic behavior (Serpa et al., 1991) were related to poorer performance. Whereas other literature has found higher levels of positive feedback (Horne \& Carron, 1985) and lower levels of autocratic behavior (Garland \& Berry, 1988; Robinson \& Carron, 1982) were related to successful performance. Additionally, the congruence hypothesis has been supported related to performance outcomes (Prati \& Pietrantoni, 2013). The literature related to the MML has spanned a variety of contexts and provided valuable insights into common coaching behavior; however, it is lacking in experimental or quasi-experimental research design which could identify causal relationships between coaching behaviors and outcomes (e.g., athlete satisfaction and performance). Despite the overarching need for experimental research design using the MML, some areas of coaching behavior would still benefit from further descriptive research, including understudied intersections of contexts such as high school settings and Eastern cultural settings.

\subsection{Purpose of the Study}

Though leadership theories have been developed for a few decades, research topics related to coaching leadership behaviors in high school settings are understudied, particularly in Hong Kong. The purpose of the study was to examine the predominant coaching leadership behaviors of high-ranking and low-ranking high school head basketball coaches in Hong Kong utilizing the Leadership Scale for Sports (LSS) (Chelladurai \& Saleh, 1980). Specifically, the following research questions would be examined:

1) Would there be significant $(p<.05)$ differences in the coaching behaviors leadership behaviors between high-ranking and low-ranking high school head basketball coaches?

2) Would there be a significant $(p<.05)$ preference of certain coaching leadership behaviors by the head basketball coaches as measured by the LSS (Chel- 
ladurai \& Saleh, 1980).

\section{Method}

The coach's self-perception version of the LSS was administered to high school head basketball coaches in Hong Kong who volunteered to participate in the study. The head coaches were those who participated in the Inter-School Basketball Boys A Grade Competition organized by the Hong Kong Schools Sports Association (HKSSA) and the New Territories Schools Sports Association (NTSSA).

\subsection{Participants}

A total of 170 basketball teams participated in the competition (78 teams with HKSSA and 92 teams with NTSSA). Each team was led by one head coach. One hundred and twelve of the 170 basketball coaches from 41 different groups were invited to be participants in this study. Based on the win/loss percentage, 56 coaches were invited from the 41 groups with the highest winning percentage (top-ranking teams) and another 56 coaches were invited from the 41 groups with the lowest winning percentage (low-ranking teams). The coach was either on the teaching staff of the school or otherwise employed by the school as a coach. As a result, 68 of the 112 coaches returned their questionnaires (a response rate of $61 \%$ ). However, only 58 questionnaires were usable (30 from the winning teams and 28 from the losing teams) for this study. Due to the unequal numbers of top-ranking and low-ranking coaches, 28 of the 30 top-ranking coaches were randomly selected in order to match the number of low-ranking coaches $(n=28)$.

\subsection{Measuring Instrument}

The LSS was introduced and developed by Chelladurai and Saleh (1980) and it is a 40-item scale consisting of five dimensions of leader behaviors: "Training and Instruction Behavior", "Democratic Behavior", "Autocratic Behavior", "Social Support Behavior", and "Positive Feedback Behavior". Three versions of the LSS are available: (a) athlete's preference, (b) athlete's perception of coach's behavior, and (c) coach's own perception of behavior. Only the coach's self-perception version was used in this study. Item responses were based on a 5-point Likert scale: always (1), often (2), occasionally (3), seldom (4), and never (5). Five points were given to "always", four points to "often", three points to "occasionally", two points to "seldom", and one point for "never". The total scores for each category were obtained by adding the scores of all the items and then dividing by the number of items in that category. The higher the scores in that category, the more obvious the behavior the subject was in that dimension. Dwyer and Fischer (1988) and Salminen and Liukkonen (1994) found that the Cronbach's alpha coefficients of the subscales, except "Autocratic Behavior", ranged from .57 to .86 and from .71 to .85 , respectively. However, the alpha 
coefficients of "Autocratic Behavior" were unacceptable (Dwyer \& Fischer, 1988; Salminen \& Liukkonen, 1994). In spite of this, Salminen and Liukkonen (1994) concluded that the LSS is a valid instrument in leadership research, though the results of the "Autocratic Behavior" should be interpreted with caution. In a more recent study, Fletcher and Roberts (2013) stated that the LSS had high level of structural stability and could be used to measure perceptions of leadership consistently over time. Likewise, Wałach-Biśta (2013) concluded that the LSS was "a reliable and valid tool" even it was translated into Polish (p. 270). Interesting, Chiu et al. (2016) reduced the LSS to 25 items and yet found the shortened version of the LSS reliable in measuring coaching behavior. Additionally, Chelladurai (2007) suggested that research has not yet concluded if the expanded factor structure of the Revised Leadership Scale for Sports (RLSS) (Zhang et al., 1997) is superior to the LSS and that in the spirit of parsimony, the shorter LSS is appropriate for continued use.

\subsection{Procedures}

A total of 170 basketball teams participated in the competition. The 170 teams were divided into 41 groups. After the competition within each group was over, one to three winning teams (teams with the highest winning percentage) and the same number of losing teams (teams with the lowest winning percentage) in each group were chosen for this study. For the group with three or four teams, the coaches of the first and the last teams in the group were invited to be subjects; for the group with five to six teams, the coaches of the first two and last two teams in the group were invited; whereas for the group with seven or eight teams, the coaches of the first three and the last three teams were invited. As a result, 112 basketball coaches were invited to be volunteers in this study: 56 coaches from the 56 winning teams (teams with the highest winning percentage) and another 56 coaches from the 56 losing teams (teams with the lowest winning percentage).

After the yearly competition was completed, a letter concerning the purpose and detail of the study and the subject consent form were sent to the head coaches. They were asked to sign and return the consent form within two weeks of receipt of the letter. The questionnaire and the demographic form were sent to the coaches after receiving their consent forms. The coach's self-perception version of the LSS, which is used to evaluate the coach's perception of his own behavior, was sent to the basketball coaches. The coaches were asked to return the questionnaire within two weeks of receipt of the letter. One week after the due date, follow-up phone calls and/or reminder letters together with the questionnaires were sent to the coaches who did not return the questionnaires. They were requested to return the questionnaire as soon as possible.

\subsection{Statistical Analysis}

This study was designed to investigate whether differences existed in the five 
dimensions of coaching leadership behaviors between the high-ranking and low ranking high school head basketball coaches. IBM SPSS Statistics 22 was used for all data analyses. A 2 (Ranking) $\times 5$ (Coaching) mixed-design ANOVA was used to examine the significant differences among those five coaching dimensions (dependent variables) for each of the head coach ranking category (independent variable).

\section{Results}

The main purpose of this study was to investigate whether differences existed in coaching leadership behaviors between high-ranking and low-ranking high school head basketball coaches in Hong Kong. The other purpose of the study was to examine whether there was a preference in the coaching leadership behaviors among the head coaches. Results of the $2 \times 5$ mixed-design ANOVA indicated there was no significant Ranking $\times$ Coaching interaction $(F[4,216]=.196$, $p=.838)$. In addition, the main effect for Ranking was also not significant ( $F[1$, $54]=.002, p=.964)$. However, significant main effect was found for Coaching $(F[4,216]=46.015, p<.001$; Partial Eta Squared $=.460$, Observed Power $=1.000)$. Post hoc pairwise comparisons showed that both top-ranking and low-ranking head basketball coaches exhibited significantly $(p<.001)$ higher level of Teaching and Instruction as well as Positive Feedback than Social Support, Democratic Behavior, and Autocratic Behavior. Meanwhile, all the coaches exercised a significantly $(p<.001)$ lower degree of Autocratic Behavior than all other four dimensions of the LSS. However, Teaching and Instruction as well as Positive Feedback were not significantly $(p>.05)$ different from each other. Likewise, no significant $(p>.05)$ difference was found between Democratic Behavior and Social Support. The overall mean scores of the five dimensions of the LSS between top-ranking and low-ranking head basketball coaches are depicted in Figure 1. The most common coaching behaviors for both the top-ranking and low-ranking coaches were, in descending order, Positive Feedback, Training and Instruction, Social Support, Democratic Behavior, and Autocratic Behavior. In summary, the results of the study indicated no significant $(p>.05)$ differences in the coaching behaviors leadership behaviors between high-ranking and low-ranking high school head basketball coaches (Research Question 1), but there was a significant $(p<.05)$ preference of coaching leadership behaviors (i.e., Teaching and Instruction as well as Positive Feedback) by the head basketball coaches over other coaching leadership behaviors (Research Question 2).

\section{Discussion}

The main purpose of the current study was to examine the differences in coaching leadership behaviors between top-ranked and low-ranked high school head basketball coaches.

Based on the results of the study, no differences in the coaching behaviors are expected between the top-ranking and low-ranking head basketball coaches. In 


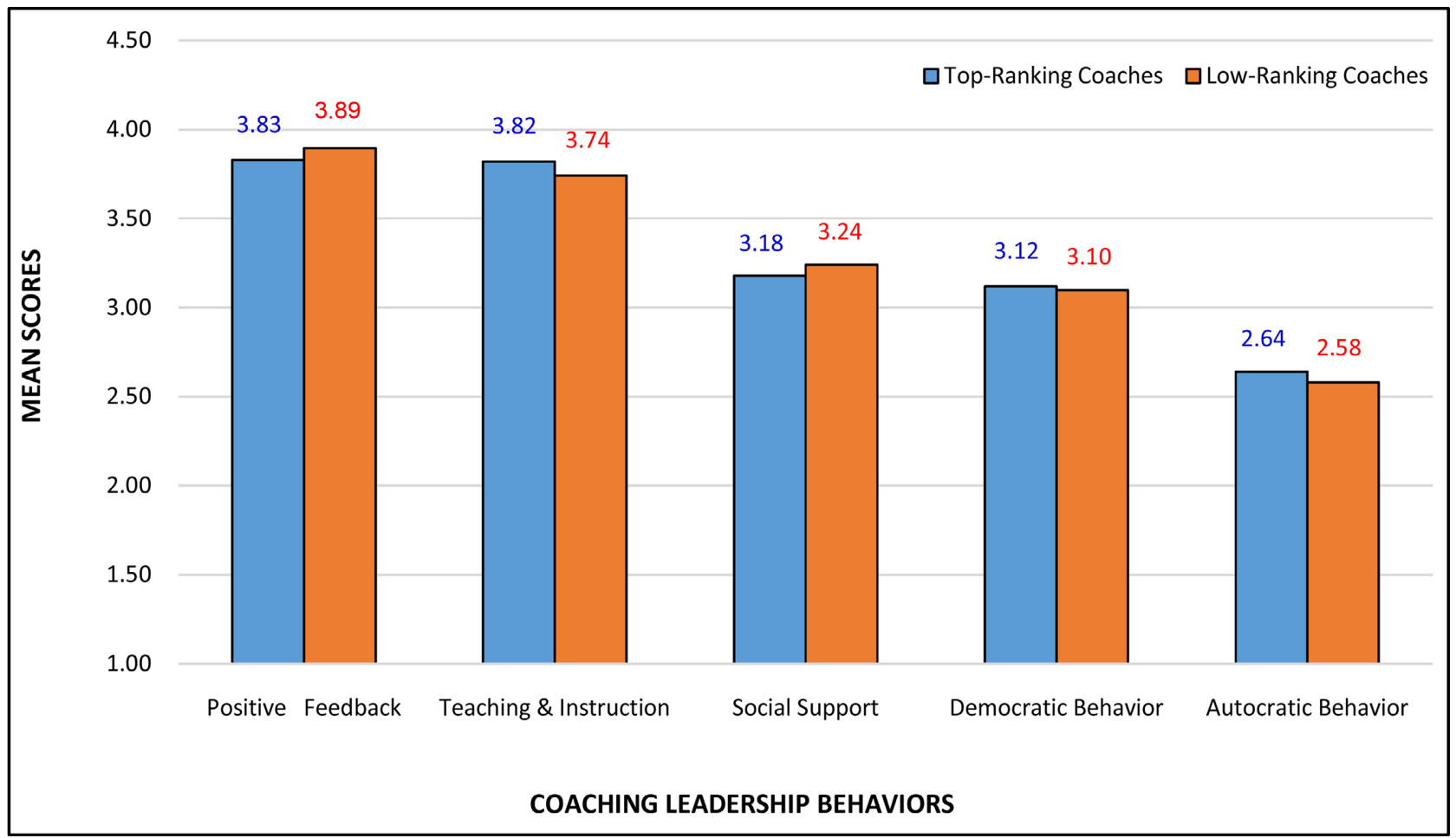

Figure 1. Mean scores of the five dimensions of the LSS between top-ranking and low-ranking head basketball coaches.

other words, it is difficult to predict the outcomes of the basketball games simply based on the coaching behaviors of the head coaches. These findings are consistent with previous research studies (e.g., Callaway, 1983; Gabriel \& Brooks, 1986). For example, Callaway (1983) found no distinguishable leadership behaviors among successful and unsuccessful collegiate women basketball coaches. In the sport of tennis, Gabriel and Brooks (1986) found no significant differences between the tennis coaches of the National Association of Intercollegiate Athletics and the National Junior College Athletic Association. They also concluded that leadership behaviors of the LSS were not significant predictors of team win/loss percentage. In a more recent study, Ganaden et al. (2017) concluded that there was no significant difference in the coaching behaviors among coaches with different profiles and experience. Similarly, LaForge et al. (2012) found that perceived coaching behaviors did not significantly differ among youth sport coaches regardless of the coaching context (competitive, instructional, or community) or whether the coaches were certified or not. However, the findings of the current study are inconsistent with those of Serpa et al., 1991). When examining 77 coaches of the national handball teams during the championship, Serpa et al. (1991) concluded that different leadership styles were found among coaches of the most successful and least successful teams.

In this study, the mean scores as determined by the five dimensions of the LSS were in the following descending order: Positive Feedback, Training and Instruction, Social Support, Democratic Behavior, and Autocratic Behavior. This results were exactly the same as in Burns' (1983) study, where he found both 
Christian and non-Christian high school coaches ranked Positive Feedback the highest and Autocratic Behavior the lowest. Ganaden et al. (2017) commented that coaches in general exhibited a lower level of autocratic behavior. Likewise, Alemu and Babu (2012) showed in their study that coaches of premier league soccer clubs exhibited high preference in Training and Instruction but low preference in Autocratic Behavior. In this study, both top-ranking and low-ranking head basketball coaches demonstrated a lesser degree of Autocratic Behavior than other coaching behaviors as determined by the LSS. One explanation for this was that in Boys A grade competitions, the athletes were more mature and had many years of basketball experience. For this reason, Autocratic Behavior might not be appropriate for those players at that skill level since it was only applicable in situations where the athletes were less mature and had lower skill levels (Robinson \& Carron, 1982). Chelladurai and Carron (1983) further commented that a reduction in the task dimension should be exercised when the members are at the highest level of maturity. In fact, young athletes strongly preferred training and instruction as well as positive feedback but least preferred autocratic behavior (Cruz \& Kim, 2017).

As mentioned before, the multi-dimensional model of coaching developed by Chelladurai and Saleh (1978) included Training and Instruction, Positive Feedback, Social Support, Democratic Behaviors, and Autocratic Behaviors. Leadership behavior exhibited by coaches will have a significant impact on individual athletes and teams (Amorose \& Horn, 2001; Martin et al., 2001; Vealey et al., 1998). In this study, both the top-ranking and low-ranking head basketball coaches exhibited a significantly higher level of Training and Instruction and Positive Feedback than the other dimensions of the LSS. This finding is comparable with other studies (e.g., Ganaden et al., 2017; Ramzaninezhad \& Keshtan, 2009). The next section will discuss the aforesaid five dimensions of coaching behaviors, starting from Training and Instruction, in more detail and their applications.

\subsection{Training and Instruction}

In this study, all the head coaches demonstrated a significantly higher level of Training and Instruction and Positive Feedback than other dimensions of coaching behaviors. These two dimensions are aimed at motivating athletes and satisfying interpersonal needs and they are the most common behaviors among coaches (Bennett \& Maneval, 1998; Chelladurai, 1984; Dwyer \& Fischer, 1990; Horne \& Carron, 1985; Kim \& Cruz, 2016; Ramzaninezhad \& Keshtan, 2009; Weiss \& Friedrichs, 1986). Segrave and Ciancio (1987) further commented that a highly successful head coach would demonstrate such behaviors as "instruction" and "praise". In fact, these two types of coaching behaviors are commonly perceived by youth athletes (LaForge et al., 2012) and they are most likely preferred by athletes (e.g., Cruz \& Kim, 2017; Nazarudin et al., 2009; Sherman et al., 2000). For example, Sherman et al. (2000) found that the most preferred coaching be- 
haviors by athletes (regardless of gender) of Australian football, netball, and basketball were Positive Feedback and Training and Instruction. Interestingly, Kwon et al. (2010) found that student-athletes perceived their coaches to provide training and instruction more often than physical education students perceived those behaviors from their physical education teachers.

The purpose of the Teaching and Instruction coaching behavior is to assist the athletes to reach their maximum physical potential and athletic performance, and it includes instruction in the skills, techniques, and tactics of their respective sport (Chelladurai, 2007). Previous studies have indicated that this coaching behavior has a strong impact on athletic performance and team dynamics (e.g., Bum \& Shin, 2015; Burkett et al., 2014; Chelladurai, 1993; Kim \& Han, 2004; Murray, 2006; Ramzaninezhad \& Keshtan, 2009; Rajabi, 2012). For example, Training and Instruction could decrease junior golfers' cognitive anxiety before the game (Bum \& Shin, 2015) and promote emotional stability, which would lead to a better performance (Kim \& Han, 2004). This is consistent with the previous study that indicated such coaching behavior could influence athletes' psychological state (Chelladurai, 1993). Other researchers agreed that team cohesion was positively correlated with the degree of Training and Instruction (e.g., Burkett et al., 2014; Murray, 2006; Ramzaninezhad \& Keshtan, 2009; Turman, 2003, 2008). Specifically, Ramzaninezhad and Keshtan (2009) showed that there was a positive correlation between training and instruction and task and social cohesion among Iran professional football athletes. Team cohesion is important in the sport setting since it is related to the performance of athletes (Carron et al., 2002). On the other hand, Alemu and Babu (2013) concluded that sport enjoyment and social constraint to continue participation in sport activities had a significant positive relationship with Training and Instruction. In summary, Training and Instruction is the most popular and essential coaching behavior that provides a favorable atmosphere for sport participants (e.g., sport enjoyment and future sport participation) and athletes (e.g., reduce anxiety and improve athletic performance) alike.

\subsection{Positive Feedback}

As mentioned before, all the head coaches in this study demonstrated a significantly higher level of Training and Instruction and Positive Feedback than other dimensions of coaching behaviors. In fact, Positive Feedback is one of the most obvious coaching behaviors perceived and preferred by athletes (Bennett \& Maneval, 1998; Cruz \& Kim, 2017; Ganaden et al., 2017; LaForge et al., 2012; Nazarudin et al., 2009). Positive Feedback is the coaching behavior that reinforces athletes by recognizing and rewarding good performance as well as providing appropriate feedback as to how well the athletes train or perform (Chelladurai, 2007). In the sports and physical education settings, positive feedback has a direct influence on the athletes' psychological responses (Horn, 2002) and is linked to perceptions of competence (Nicaise et al., 2006) as well as intrinsic motivation 
(Reinboth et al., 2004). In a sample of young athletes from various sports, Amorose and Horn (2001) indicated that coaching behaviors consisting of positive, supportive, and informational feedback predicted interest, enjoyment, and perceived competence. Likewise, Allen and Howe (1998) found that informative positive as well as encouraging feedback after mistakes was related to perceived competence and satisfaction in female hockey players. In the physical education setting, Koka and Hein (2003) found that perceived positive instructor feedback predicted students' perceptions of competence and intrinsic motivation.

Athletes in general are more likely to experience feelings of success and competence when they are provided with positive encouragement and proper feedback than when they are criticized repeatedly (Black \& Weiss, 1992). For those athletes who received positive feedback, they would show higher self-efficacy, performed the task better, and chose more difficult tasks than those who had received negative feedback (Escarti \& Guzman, 1999). When dealing with young or inexperience athletes, Barnett et al. (1992) asserted that positive, rewarding feedback given as a result of a good effort or specific instruction on how to correct a mistake maximizes the positive experience of athletes, particularly those with low self-esteem. Mouratidis et al. (2008) also showed that positive feedback from coaches could positively predict satisfaction, vitality, and intention to participate. After studying over 500 soccer players aged from 13 to 20 years old, Høigaard et al. (2017) found that positive/instructive feedback with a sense of humor could develop team identity among young players. More recently, Cranmer, Brann, and Weber (2018) found that athletes exhibited more satisfaction and higher motivation when their coaches challenge them through constructive criticism and a focus on development. In summary, athletes who perceived receiving more positive and informational feedback, less criticism or punishment, tended to report more positive achievement-related outcomes, including higher levels of perceived competence. When athletes have the freedom to withdraw from the sport or switch teams, positive feedback is one of the major coaching behaviors that can enhance athlete satisfaction and retention as well as their future sport involvement (Mouratidis et al., 2008; Smoll \& Smith, 2002).

\subsection{Social Support}

In this study, Social Support is the third most common coaching behaviors exhibited by both the top-ranked and low-ranked high school head basketball coaches. Social support is a crucial element of coaching behavior (Chelladurai \& Saleh, 1978, 1980) and it is characterized by a concern for the welfare of individual athletes that includes positive group atmosphere and warm interpersonal relations with members (Chelladurai, 2007). According to Reinboth et al. (2004), the Social Support coaching behavior perceived by players was a strong positive predictor of athletes' sense of relatedness within their team. This finding is also 
backed by the self-determination theory that indicates showing care for and valuing those as individuals would lead to them feeling more valued and attached to others in the setting (Deci \& Ryan, 2000; Ryan \& Solky, 1996). Meanwhile, Rees and colleagues concluded that social support could have an impact on athletic performance. For example, social support might be associated with performance-related variables (e.g., stress reduction) during competition in tennis (Rees \& Hardy, 2000, 2004) and it had a strong positive main effect on the performance of golf players (Rees et al., 2007). Interestingly, Hardy et al. (1991) asserted that several dimensions of social support were predictive of the frequency of injury among intercollegiate male athletes.

Since self-talk is related to athletic performance, Weinberg et al. (1992) examined strategies used by Australian and American coaches to enhance athletes' self-efficacy and found that one of the most frequently used strategies was using rewarding statements to facilitate athletes' positive self-talk. Later, Zourbanos et al. (2006) discovered that coaches' supportiveness could predict coaches' esteem support, which in turn predicted athletes' positive self-talk. In other words, coaches' esteem support played an important role in mediating the relationship between general supportive behavior and athletes' positive self-talk. Further, athletes' satisfaction with their sport experiences has been found to be increased with their coaches' use of supportive communication (Cranmer \& Sollitto, 2015). In summary, the way the coaches expressed their feedback had a strong influence on athletes' way of thinking. For this reason, coaches are recommended to use supportive verbalizations in their instructions (Hardy \& Crace, 1991) and provide their feedback in a supportive manner (e.g., with encouraging comments and verbal rewards) that enhances positive thinking of the athletes which in turn generates facilitative effects on athletic performance (Van Raalte et al., 1994). On the contrary, coaches' negative behavior can initiate negative thoughts in athletes' minds that might be detrimental for athletic performance (Van Raalte et al., 1994).

\subsection{Democratic Behavior versus Autocratic Behavior}

In this study, both the top-ranked and low-ranked high school head basketball coaches demonstrated a significantly higher level of Democratic Behavior than Autocratic Behavior. Democratic coaching behavior allows greater athlete participation in decisions pertaining to group goals, practice methods, as well as game tactics and strategies (Chelladurai, 2007). On the contrary, autocratic coaching behavior is a dominating form of behavior that involves independence in decision making and stresses personal authority over the athletes (Chelladurai, 2007). The Democratic Behavior of the coach is aimed at promoting the coach-athlete relationship, which not only has a direct effect on coaching effectiveness, but also has an impact on athletes' performance. However, the effectiveness of athletic performance is heavily relied on the degree of closeness between the coach and the athletes (Jowett, 2006). Previous research has indicated 
that a high-quality coach-athlete relationship is more likely to enhance the desired athletic outcomes than a poor coach-athlete relationship (e.g., Vella et al., 2010). Other researchers have also showed that coaches' democratic behavior can promote athletes' positive relations, which lead to a positive group climate (Shohani et al., 2014). The benefit of involving athletes in making choices process is that it can promote their skill development and decision making ability (Stewart \& Owens, 2011). In fact, athletes were more satisfied with their experience when they were involved in making decisions regarding their training or practice (Felton \& Jowett, 2013). When examining over 200 high school athletes, Lee et al. (2017) concluded that there was a positive relationship between athletes' social responsibility and coaches' democratic behavior while it had a negative relationship with the coaches' autocratic behavior. Ramzaninezhad and Keshtan (2009) also showed that there was a negative correlation between autocratic behavior and task and social cohesion among Iran professional football athletes. In the physical education stetting, Koka (2013) concluded that students who perceived their teachers included them in the decision-making process (i.e., adopting democratic behavior and avoiding autocratic behavior) experienced a higher level of autonomous motivation in physical education.

Studies in general have shown that democratic behavior is preferred by females than males. For example, Beam et al. (2004) found that male student-athletes showed significantly greater preferences for autocratic behavior while female athletes tended to prefer a more democratic leadership behavior. Likewise, Chelladurai and Saleh (1978) and Terry (1984) also showed that male physical education majors and elite athletes had a significantly higher preference for autocratic leader behavior. In their study, Amorose and Horn (2001) demonstrated that democratic behavior was more important to female athletes' intrinsic motivation than male athletes. In their study of 193 female soccer players, Price and Weiss (2000) concluded that female athletes' perceptions of greater training and instruction, social support, positive feedback, democratic decisions, and less autocratic behavior were related to more positive (i.e., perceived competence, enjoyment) and less negative (i.e., anxiety, burnout) psychological outcomes.

Nevertheless, it does not mean that democratic behavior plays a more important role than autocratic behavior. For example, Sherman (1996) found that coaches from baseball, soccer, and tennis sports used more autocratic behavior during exercise and competition and further commented that young and inexperienced trainers tended to use this behavior in order to control and manage exercises and dominate athletes. According to Bekiari (2014), coaches of contact sports (e.g., basketball and football) tended to adopt autocratic behavior when compared to non-contact sports (e.g., volleyball, track and field). The reason is that the high level of competitiveness and tension among athletes in contact sports requires coaches to adopt a more "aggressive" profile to counterbalance the demands of the game (Bekiari et al., 2006). When examining football players' 
perceived and preferred leadership behavior, Riemer and Chelladurai (1995) found that defensive football players reported greater preferences and perceived greater amounts of democratic and autocratic behavior than did offensive players. Coaching behaviors may also change during the competition cycle. For example, Turman (2003) found that both athletes' preferences and perception of coaches' autocratic behaviors were higher at the middle and at the end of the season.

\subsection{Limitations of the Study}

As in all research studies, there are limitations to the current study. First, the LSS was developed in North America and has never been validated in other cultures, some of the items may not be appropriate to other population (Zhang, 1993). In this study, only the coach's self-perception version of the LSS was used. Therefore, the results were confined to the subjective ratings of the coaches themselves, whereas the actual leadership behaviors of the coaches were not determined objectively (e.g., athletes may perceive the coaching behaviors more negatively than do the coaches themselves (Kenow \& Williams, 1992; Misasi et al., 2016). For this reason, the athlete's preference and perception of coach's behavior versions of the LSS can be distributed to the athletes so that the preferred and perceived coaching behaviors of the athletes can be compared with the coaches' own perceived coaching behaviors.

According to Ryckman and Daniel (1980), to measure leadership and leader behavior effectiveness is very complex. Therefore, future studies should also include other observational instruments to determine actual behaviors of the coaches, such as the Coaching Behavior Questionnaire (Williams et al., 2003) and the Coaching Behavior Scale for Sports (Cote et al., 1999). While this study is concentrated on the behaviors of the coaches, future studies should also include teammates and parents since the motivational climate comes not just from the coaches, but also from parents and peers since parents can provide support and facilitation, and peers can affect motivation through competitive behaviors, collaborative behaviors, evaluative communications, and social relationships (Keegan et al., 2010). Besides, Wandzilak et al. (1988) found that youth sport soccer coaches used more instructional/organizational and negative comments during practices, but more encouraging remarks in games. Future studies can compare and distinguish the differences in coaching behaviors between practices and in real game situations. In Hong Kong, very little, if any, research has been done on coaching leadership behaviors. The scope of this study is limited to coaching behaviors of head basketball coaches and cannot be generalized to the whole population. Therefore, there is a need for replication of this research, with a much greater number of participants representing other sports. Besides, future studies should expand the sample representations (e.g., to include other regions or countries) to make the study more generalizable. 


\section{Conclusion}

The purpose of the study was to examine the differences in coaching leadership behaviors between top-ranked and low-ranked high school head basketball coaches. The results indicated no differences in the coaching behaviors between the top-ranking and low-ranking high school head basketball coaches. However, both top-ranking and low-ranking head coaches exhibited significantly higher level of Teaching and Instruction as well as Positive Feedback than Social Support, Democratic Behavior, and Autocratic Behavior as measured by the LSS. In conclusion, each coaching behavior has its own functions and roles as well as its own advantages and disadvantages in the sport setting. It is unwise to say that one coaching behavior is better than the other since the application of coaching behavior is depends on the competition level and game situation. For example, though it is not welcome by most female athletes, the autocratic behavior is an effective tool among elite athletes or more experienced players. For these reasons, coaches should implement the right coaching behavior at the right moment in the right place to the right athletes.

\section{Conflicts of Interest}

The authors declare no conflicts of interest regarding the publication of this paper.

\section{References}

Aleksic-Veljkovic, A., Djurovic, D., Dimic, I., Mujanovic, R., \& Zivcic-Markovic, K. (2016). College Athletes' Perceptions of Coaching Behaviours: Differences between Individual and Team Sports. Baltic Journal of Sport and Health Sciences, 2, 61-65. https://doi.org/10.33607/bjshs.v2i101.57

Alemu, S. M., \& Babu, M. S. (2012). The Relationship between Coaches' Leadership Styles, Team Cohesion and Team Success: The Case of Premier League Soccer Clubs in Ethiopia. International Journal of Social Science \& Interdisciplinary Research, 1, 1-12.

Alemu, S. M., \& Babu, S. (2013). Football Coach Leadership Styles and Players Commitment. National Monthly Refereed Journal of Research in Commerce \& Management, 2, 110-121.

Allen, J. B., \& Howe, B. L. (1998). Player Ability, Coach Feedback, and Female Adolescent Athletes' Perceived Competence and Satisfaction. Journal of Sport \& Exercise Psychology, 20, 280-299. https://doi.org/10.1123/jsep.20.3.280

Amorose, A. J., \& Horn, T. S. (2001). Pre- to Post-Season Changes in the Intrinsic Motivation of First-Year College Athletes: Relationships with Coaching Behavior and Scholarship Status. Journal of Applied Sport Psychology, 13, 355-373. https://doi.org/10.1080/104132001753226247

Andrew, D. P. S. (2009). The Impact of Leadership Behavior on Satisfaction of College Tennis Players: A Test of the Leadership Behavior Congruency Hypothesis of the Multidimensional Model of Leadership. Journal of Sport Behavior, 32, 261-277.

Barnett, N. P., Smoll, F. L., \& Smith, R. E. (1992). Effects of Enhancing Coach-Athlete Relationship on Youth Sport Attrition. The Sport Psychologist, 6, 111-127.

https://doi.org/10.1123/tsp.6.2.111 
Beam, J. W., Serwatka, T. S., \& Wilson, W. J. (2004). Preferred Leadership of NCAA Division I and II Intercollegiate Student-Athletes. Journal of Sport Behavior, 27, 3-17.

Bekiari, A. (2014). Verbal Aggressiveness and Leadership Style of Sports Instructors and Their Relationship with Athletes' Intri[n]sic Motivation. Creative Education, 5, 114-121. https://doi.org/10.4236/ce.2014.52018

Bekiari, A., Digelidis, N., \& Sakellariou, K. (2006). Perceived Verbal Aggressiveness of Coaches in Volleyball and Basketball: A Preliminary Study. Psychological Reports, 103, 526-530. https://doi.org/10.2466/pms.103.2.526-530

Bennett, G., \& Maneval, M. (1998). Leadership Styles of Elite Dixie Youth Baseball Coaches. Perceptual and Motor Skills, 87, 754.

https://doi.org/10.2466/pms.1998.87.3.754

Black, J. S., \& Weiss, M. R. (1992). The Relationship among Perceived Coaching Behaviors, Perceptions of Ability, and Motivation in Competitive Age-Group Swimmers. Journal of Sport and Exercise Psychology, 14, 309-325. https://doi.org/10.1123/jsep.14.3.309

Bloom, G. A., \& Salmela, J. H. (2000). Personal Characteristics of Expert Team Sport Coaches. Journal of Sport Pedagogy, 6, 56-76.

Bum, C. H., \& Shin, S. H. (2015). The Relationships between Coaches' Leadership Styles, Competitive State Anxiety, and Golf Performance in Korean Junior Golfers. Sport Science Review, 24, 371-386. https://doi.org/10.1515/ssr-2015-0024

Burkett, B. M., Blom, L. C., Razon, S., \& Johnson, J. E. (2014). Formal and Informal Athlete Leaders: The Relationship between Athlete Leadership Behaviors and Cohesion. The Journal of Sport, 3, 2-29. https://doi.org/10.21038/sprt.2014.0311

Burns, C. A. (1983). Perceptions of Ideal Leadership Behavior: Christian versus Non-Christian Women High School Coaches. University Microfilms.

Callaway, D. J. (1983). A Comparison of Leadership Styles of Successful and unsuccessful Collegiate Women Basketball Coaches. University Microfilms.

Carron, A. V., Colman, M. M., Wheeler, J., \& Stevens, D. (2002). Cohesion and Performance in Sport: A Meta Analysis. Journal of Sport and Exercise Psychology, 24, 168-188. https://doi.org/10.1123/jsep.24.2.168

Cassidy, T. G., Jones, R. L., \& Potrac, P. (2008). Understanding Sports Coaching: The Social, Cultural and Pedagogical Foundations of Coaching Practice. Routledge. https://doi.org/10.4324/9780203892923

Chase, M. A. (2010). Should Coaches Believe in Innate Ability? The Importance of Leadership Mindset. Quest, 62, 296-307. https://doi.org/10.1080/00336297.2010.10483650

Chelladurai, P. (1978). A Multidimensional Model of Leadership. Unpublished Doctoral Dissertation, University of Waterloo.

Chelladurai, P. (1984). Discrepancy between Preferences and Perceptions of Leadership Behavior and Satisfaction of Athletes in Varying Sports. Journal of Sport Psychology, 6, 27-41. https://doi.org/10.1123/jsp.6.1.27

Chelladurai, P. (1990). Leadership in Sports: A Review. International Journal of Sport Psychology, 21, 328-354.

Chelladurai, P. (1993). Leadership. In R. N. Singer, M. Murphy, \& L. K. Tennant (Eds.), Handbook of Research on Sport Psychology (pp. 647-671). Macmillan.

Chelladurai, P. (2001). Managing Organization for Sport and Physical Activity: A Systems Perspective. Holcomb-Hathaway.

Chelladurai, P. (2007). Leadership in Sports. In G. Tenenbaum \& R. C. Eklund (Eds.), 
Handbook of Sport Psychology (3rd ed., pp. 113-135). John Wiley \& Sons. https://doi.org/10.1002/9781118270011.ch5

Chelladurai, P., \& Carron, A. V. (1983). Athletic Maturity and Preferred Leadership. Journal of Sport Psychology, 5, 371-380. https://doi.org/10.1123/jsp.5.4.371

Chelladurai, P., \& Reimer, H. A. (1998). Measurement of Leadership in Sport. In J. Duda (Ed.), Advances in Sport and Exercise Psychology measurement (pp. 227-253). Fitness Information Technology.

Chelladurai, P., \& Saleh, S. D. (1978). Preferred Leadership in Sports. Canadian Journal of Applied Sport Sciences, 3, 85-92.

Chelladurai, P., \& Saleh, S. D. (1980). Dimensions of Leader Behavior in Sports: Development of a Leadership Scale. Journal of Sport Psychology, 2, 34-45.

https://doi.org/10.1123/jsp.2.1.34

Chelladurai, P., Haggerty, T. R., \& Baxter, P. R. (1989). Decision Style Choices of University Basketball Coaches and Players. Journal of Sport and Exercise Psychology, 11, 201-215. https://doi.org/10.1123/jsep.11.2.201

Chelladurai, P., Malloy, D., Imamura, H., \& Yamaguchi, Y. (1987). A Cross-Cultural Study of Preferred Leadership in Sports. Canadian Journal of Sport Sciences, 12, 106-110.

Chiu, W., Rodriquez, F. M., \& Won, D. (2016). Revisiting the Leadership Scale for Sport: Examining Factor Structure through Exploratory Structural Equation Modelling. Psychological Reports, 119, 435-449. https://doi.org/10.1177/0033294116662880

Cote, J., Yardley, J., Hay, J., Sedgwick, W., \& Baker, J. R. (1999). An Exploratory Examination of the Coaching Behavior Scale for Sport. AVANTE, 5, 82-92.

Cranmer, G. A., \& Sollitto, M. (2015). Sport Support: Received Social Support as a Predictor of Athlete Satisfaction. Communication Research Reports, 32, 253-264.

https://doi.org/10.1080/08824096.2015.1052900

Cranmer, G. A., Brann, M., \& Weber, K. D. (2018). “Challenge Me!” Using Confirmation Theory to Understand Coach Confirmation as an Effective Coaching Behavior. Communication \& Sport, 6, 239-259. https://doi.org/10.1177/2167479516684755

Cruz, A. B., \& Kim, H. (2017). Leadership Preferences of Adolescent Players in Sport: Influence of Coach Gender. Journal of Sports Science and Medicine, 16, 172-179.

Deci, E. L., \& Ryan, R. M. (2000). The "What" and "Why" of Goal Pursuits: Human Needs and the Self-Determination of Behavior. Psychological Inquiry, 11, 227-268. https://doi.org/10.1207/S15327965PLI1104_01

Dwyer, J. J., \& Fischer, D. G. (1988). Psychometric Properties of the Coach's Version of Leadership Scale for Sports. Perceptual and Motor Skills, 67, 795-798. https://doi.org/10.2466/pms.1988.67.3.795

Dwyer, J. J., \& Fischer, D. G. (1990). Wrestlers' Perceptions of Coaches' Leadership as Predictors of Satisfaction with Leadership. Perceptual and Motor Skills, 71, 511-517. https://doi.org/10.2466/pms.1990.71.2.511

Escarti, A., \& Guzman, J. F. (1999). Effects of Feedback on Self-Efficacy, performance, and Choice in an Athletic Task. Journal of Applied Sport Psychology, 11, 83-96. https://doi.org/10.1080/10413209908402952

Felton, L., \& Jowett, S. (2013). "What Do Coaches Do" and "How Do They Relate": Their Effects on Athletes' Psychological Needs and Functioning. Scandinavian Journal of Medicine \& Science in Sports, 23, e130-e139. https://doi.org/10.1111/sms.12029

Fletcher, R. B., \& Roberts, M. H. (2013). Longitudinal Stability of the Leadership Scale for Sports. Measurement in Physical Education and Exercise Science, 17, 89-104. 
https://doi.org/10.1080/1091367X.2013.761021

Gabriel, L., \& Brooks, D. (1986). An Investigation of the Leadership Behavior of Selected NAIA and NJCAA Women's Tennis Coaches. Paper Presented at the Meeting of North American Society for the Sociology of Sport, Las Vegas, Nevada.

Gama, D. R. N. D., Nunes, R. D. A. M., Castro, J. B. P. D., Souza, C. A. M. D., Rodrigues Júnior, F. L., \& Vale, R. G. D. S. (2019). Analysis of the Relationship between Personality Traits and Leadership Characteristics of Handball Coaches of School Teams in the State of Rio de Janeiro, Brazil. Motriz: Revista de Educação Física, 25, Article ID: e101925. https://doi.org/10.1590/s1980-6574201900030014

Ganaden, A. R., Ejaus, E., \& De Guzman, M. D. (2017). Leadership Behaviors of Sports Coaches in Public Elementary Schools of District 2, San Felipe, Zambales, Philippines. Asia Pacific Journal of Education, Arts and Sciences, 4, 65-71.

Garland, D. J., \& Barry, J. R. (1988). The Effects of Personality and Perceived Leader Behavior of Performance in Collegiate Football. Psychological Record, 38, 237-247. https://doi.org/10.1007/BF03395019

Hardy, C. J., \& Crace, R. K. (1991). Social Support within Sport. Sport Psychology Training Bulletin, 3, 1-8.

Hardy, J., Gam Hardy, C. J., Richman, J. M., \& Rosenfeld, L. B. (1991). The Role of Social Support in the Life Stress/Injury Relationship. Sport Psychologist, 5, 128-139. https://doi.org/10.1123/tsp.5.2.128

Hersey, P., \& Blanchard, K. (1982). Management of Organizational Behavior: Utilizing Human Resources (4th ed.). Prentice-Hall.

Høigaard, R., Haugen, T., Johansen, B. T., \& Giske, R. (2017). Team Identity in Youth Soccer: The Role of Coaches' Feedback Patterns and Use of Humour. International Journal of Sports Science \& Coaching, 12, 697-707. https://doi.org/10.1177/1747954117738843

Høigaard, R., Jones, G. W., \& Peters, D. M. (2008). Preferred Coach Leadership Behavior in Elite Soccer in Relation to Success and Failure. International Journal of Sports Science \& Coaching, 3, 241-250. https://doi.org/10.1260/174795408785100581

Horn, T. S. (2002). Coaching Effectiveness in the Sport Domain. In T.S. Horn (Ed.), Advances in Sport Psychology (pp. 309-354). Human Kinetics.

Horn, T. S. (2008). Coaching Effectiveness in the Sport Domain. In T.S. Horn (Ed.), Advances in Sport Psychology (3rd ed., pp. 239-267). Human Kinetics.

Horn, T. S., Bloom, P., Berglund, K. M., \& Packard, S. (2011). Relationship between Collegiate Athletes' Psychological Characteristics and Their Preferences for Different Types of Coaching Behavior. The Sport Psychologist, 25, 190-211. https://doi.org/10.1123/tsp.25.2.190

Horne, T., \& Carron, A. V. (1985). Compatibility in Coach-Athlete Relationships. Journal of Sports Psychology, 7, 137-149. https://doi.org/10.1123/jsp.7.2.137

House, R. J. (1971). A Path-Goal Theory of Leader Effectiveness. Administrative Science Quarterly, 16, 321-339. https://doi.org/10.2307/2391905

Johnson, S. R., Wojnar, P. J., Price, W. J., Foley, T. J., Moon, J. R., Esposito, E. N., \& Cromartie, F. J. (2011). A Coach's Responsibility: Learning How to Prepare Athletes for Peak Performance. The Sports Journal.

http://thesportjournal.org/article/a-coachs-responsibility-learning-how-to-prepare-athl etes-for-peak-performance/

Jowett, S. (2006). Interpersonal and Structural Features of Greek Coach-Athlete Dyads Performing in Individual Sports. Journal of Applied Sport Psychology, 18, 69-81. 
https://doi.org/10.1080/10413200500471335

Kao, S. F., Chen, Y. F., Watson, J. C., \& Halbrook, M. (2015). Relationships between the Congruence of Required and Perceived Leadership Behavior and Satisfaction in Athletes. Psychological Reports, 117, 391-405. https://doi.org/10.2466/01.07.PR0.117c16z4

Keegan, R., Spray, C.M., Harwood, C., \& Lavallee, D. (2010). The Motivational Atmosphere in Youth Sport: Coach, Parent and Peer Influences on Motivation in Specializing Sport Participants. Journal of Applied Sport Psychology, 22, 87-105. https://doi.org/10.1080/10413200903421267

Kenow, L, J., \& Williams, J. M. (1992). Relationship between Anxiety, Self-Confidence, and Evaluation of Coaching Behaviors. Sport Psychologist, 6, 344-357. https://doi.org/10.1123/tsp.6.4.344

Kim, H. D., \& Cruz, A. B. (2016). The Influence of Coaches' Leadership Styles on Athletes' Satisfaction and team Cohesion: A Meta-Analytic Approach. International Journal of Sports Science \& Coaching, 11, 900-909. https://doi.org/10.1177/1747954116676117

Kim, K. H., \& Han, K. H. (2004). Golf. Rainbowbook.

Koka, A. (2013). The Relationships between Perceived Teaching Behaviors and Motivation in Physical Education: A One-Year Longitudinal Study. Scandinavian Journal of Educational Research, 57, 33-53. https://doi.org/10.1080/00313831.2011.621213

Koka, A., \& Hein, V. (2003). Perceptions of Teacher's Feedback and Learning Environment as Predictors of Intrinsic Motivation in Physical Education. Psychology of Sport and Exercise, 4, 333-346. https://doi.org/10.1016/S1469-0292(02)00012-2

Kwon, H. H., Pyun, D. Y., \& Kim, M. (2010). Perceived Leadership Behavior of Physical Education Teacher-Coaches: When They Teach vs. When They Coach. Journal of Teaching in Physical Education, 29, 131-145. https://doi.org/10.1123/jtpe.29.2.131

LaForge, K., Sullivan, P. J., \& Bloom, G. A. (2012). Coaching Behaviors in Canadian Youth Sport. Athletic Insight, 4, 251-263.

Lee, Y. H., \& Chelladurai, P. (2018). Emotional Intelligence, Emotional Labor, Coach Burnout, Job Satisfaction, and Turnover Intention in Sport Leadership. European Sport Management Quarterly, 18, 393-412. https://doi.org/10.1080/16184742.2017.1406971

Lee, Y. H., Hwang, S., \& Choi, Y. (2017). Relationship between Coaching Leadership Style and Young Athletes' Social Responsibility. Social Behavior and Personality, 45, 1385-1396. https://doi.org/10.2224/sbp.6176

Lindauer, J. (2000). A Comparison of Preferred Coaching Leadership Behaviors of College Athletes in Individual and Team Sports. Unpublished Master's Thesis, University of Wisconsin-La Crosse.

Lyle, J. (2005). Coaching Styles. In J. Lyle (Ed.), Sports Coaching Concepts: A Framework for Coaches' Behavior (p. 156). Routledge.

Martin, S. D., Dale, G. A., \& Jackson, A. W. (2001). Youth Coaching Preferences of Adolescent Athletes and Their Parents. Journal of Sport Behavior, 24, 197-212.

Misasi, S. P., Morin, G., \& Kwasnowski, L. (2016, July 1). Leadership: Athletes and Coaches in Sport. The Sport Journal. http://thesportjournal.org/article/leadership-athletes-and-coaches-in-sport/

Mouratidis, A., Vansteenkiste, M., Lens, W., \& Sideridis, G. (2008). The Motivating Role of Positive Feedback in Sport and Physical Education: Evidence for a Motivational Model. Journal of Sport and Exercise Psychology, 30, 240-268.

https://doi.org/10.1123/jsep.30.2.240

Murray, N. P. (2006). The Differential Effect of Team Cohesion and Leadership Behavior 
in high school Sports. Individual Differences Research, 4, 216-225.

Mwai, E. (2011). Creating Effective Leader's through Situational Leadership Approach. Bachelor's Thesis, JAMK University of Applied Sciences.

https://www.theseus.fi/handle/10024/33027

Nazarudin, M. N. B., Omar-Fauzee, M. S., Jamalis, M., Geok, S. K., \& Din, A. (2009). Coaching Leadership Styles and Athlete Satisfactions among Malaysian University Basketball Team. Research Journal of International Studies, 9, 4-11.

Nicaise, V., Cogérino, G., Bois, J., \& Amorose, A. (2006). Students' Perceptions of Teacher Feedback and Physical Competence in Physical Education Classes: Gender Effects. Journal of Teaching in Physical Education, 25, 36-57. https://doi.org/10.1123/jtpe.25.1.36

Prati, G., \& Pietrantoni, L. (2013). The Effects of Congruency and Discrepancy of Sport Leadership Behaviors on Objective Performance. International Journal of Sport Psychology, 44, 546-564. https://doi.org/10.1123/tsp.14.4.391

Price, M. S., \& Weiss, M. R. (2000). Relationships among Coach Burnout, Coach Behaviors, and Athletes' Psychological Responses. Sport Psychologist, 14, 391-409.

Pyun, D. Y., Kwon, H. H., Koh, K. T., \& Wang, C. K. J. (2010). Perceived Coaching Leadership of Youth Athletes in Singapore. Journal of Sport Behavior, 33, 25-41.

Rajabi, Z. (2012). Relationship of Coach's Leadership Style and Player Performance Outcomes. European Journal of Experimental Biology, 2, 1134-1136.

Ramzaninezhad, R., \& Keshtan, M. H. (2009). The Relationship between Coach[es'] Leadership Styles and Team Cohesion in Iran Football Clubs Professional League. Brazilian Journal of Biomotricity, 3, 111-120.

Rees, T., \& Hardy, L. (2000). An Investigation of the Social Support Experiences of High-Level Sports Performers. The Sport Psychologist, 14, 327-347. https://doi.org/10.1123/tsp.14.4.327

Rees, T., \& Hardy, L. (2004). Matching Social Support with Stressors: Effects on Factors Underlying Performance in Tennis. Psychology of Sport and Exercise, 5, 319-337. https://doi.org/10.1016/S1469-0292(03)00018-9

Rees, T., Hardy, L., \& Freeman, P. (2007). Stressors, Social Support, and Effects upon Performance in Golf. Journal of Sports Sciences, 25, 33-42. https://doi.org/10.1080/02640410600702974

Reinboth, M., Duda, J. L., \& Ntoumanis, N. (2004). Dimensions of Coaching Behavior, Need Satisfaction, and the Psychological and Physical Welfare of Young Athletes. Motivation and Emotion, 28, 297-313. https://doi.org/10.1023/B:MOEM.0000040156.81924.b8

Riemer, H. A. (2007). Multidimensional Model of Coach Leadership. In S. Jowett \& D. Lavallee (Eds.), Social Psychology in Sport (pp. 57-74). Human Kinetics. https://doi.org/10.5040/9781492595878.ch-005

Riemer, H. A., \& Chelladurai, P. (1995). Leadership and Satisfaction in Athletics. Journal of Sport \& Exercise Psychology, 17, 276-293. https://doi.org/10.1123/jsep.17.3.276

Riemer, H. A., \& Toon, K. (2001). Leadership and Satisfaction in Tennis: Examination of Congruence, Gender, and Ability. Research Quarterly for Exercise and Sport, 72, 243-256. https://doi.org/10.1080/02701367.2001.10608957

Robinson, T., \& Carron, A. (1982). Personal and Situational Factors Associated with Dropping out versus Maintaining Participation in Competitive Sport. Journal of Sport Psychology, 4, 364-378. https://doi.org/10.1123/jsp.4.4.364

Ryan, R. M., \& Solky, J. A. (1996). What Is Supportive about Social Support? On the Psy- 
chological Needs for Autonomy and Relatedness. In G. R. Pierce, B. R. Sarason, \& I. G. Sarason (Eds.), Handbook of Social Support and the Family (pp. 249-267). Plenum. https://doi.org/10.1007/978-1-4899-1388-3_11

Ryckman, R., \& Daniel, J. V. (1980). Leadership Theory: An Overview. In P. Klavora, \& K. A. W. Wipper (Eds.), Psychological and Sociological Factors in Sport (pp. 89-96). University of Toronto, School of Physical and Health Education.

Ryska, T. A. (2009). Multivariate Analysis of Program Goals, Leadership Style, and Occupational Burnout among Intercollegiate Sport Coaches. Journal of Sport Behavior, 32, 476-488.

Salminen, S., \& Liukkonen, J. (1994). The Convergent and Discriminant Validity of the Coach's Version of the Leadership Scale for Sports. International Journal of Sport Psychology, 25, 119-127.

Segrave, J. O., \& Ciancio, C. A. (1987). An Observation Study of a Successful Pop Warner Football Coach. Journal of Teaching in Physical Education, 9, 294-306. https://doi.org/10.1123/jtpe.9.4.294

Serpa, S., Pataco, V., \& Santos, F. (1991). Leadership Patterns in Handball International Competition. International Journal of Sport Psychology, 22, 78-79.

Sherman, C. A., Fuller, R., \& Speed, H. D. (2000). Gender Comparisons of Preferred Coaching Behaviors in Australian Sports. Journal of Sport Behavior, 23, 389-406.

Sherman, M. A. (1996). Investigate of Young Sport Coach Behavior. Journal of Sport Management, 10, 27-35.

Shohani, M. H., Nabati, M., Shirzadi, R., Majedi, S. M., \& Nasiri, M. (2014). The Relationship between Leadership Styles of Coaches and Sport Commitment among Iran's Footballers Premiership League. European Journal of Experimental Biology, 4, 440-445.

Smith, R. E. (2006). Understanding Sport Behavior: A Cognitive-Affective Processing Systems Approach. Journal of Applied Sport Psychology, 18, 1-27. https://doi.org/10.1080/10413200500471293

Smoll, F. L., \& Smith, R. E. (2002). Coaching Behavior Research and Intervention in Youth Sports. In F. L. Smoll \& R. E. Smith (Eds.), Children and Youth in Sport: A Biopsychological Perspective (2nd ed., pp. 211-234). Kendall/Hunt.

Stewart, C., \& Owens, L. (2011). Behavioral Characteristics of 'Favorite' Coaches: Implications for Coach Education. Physical Educator, 68, 90-97.

Sullivan, P., Paquette, K. J., Holt, N. L., \& Bloom, G. A. (2012). The Relation of Coaching Context and Coach Education to Coaching Efficacy and Perceived Leadership Behaviors in Youth Sport. The Sport Psychologist, 26, 122-134. https://doi.org/10.1123/tsp.26.1.122

Terry, P. C. (1984). The Coaching Preferences of Elite Athletes Competing at the Universaide '83. The Canadian Journal of Applied Sports Sciences, 9, 201-208.

Terry, P. C., \& Howe, B. L. (1984). The Coaching Preferences of Athletes. The Canadian Journal of Applied Sport Sciences, 9, 188-193.

Turman, P. D. (2003). Coaches and Cohesion: The Impact of Coaching Techniques on Team Cohesion in the Small Group Sport Setting. Journal of Sport Behavior, 26, 86-104.

Turman, P. D. (2008). Coaches' Immediacy Behaviors as Predictors of Athletes' Perceptions of Satisfaction and Team Cohesion. Western Journal of Communication, 72, 162-179. https://doi.org/10.1080/10570310802038424

Vallée, C. N., \& Bloom, G. A. (2005). Building a Successful University Program: Key and Common Elements of Expert Coaches. Journal of Applied Sport Psychology, 17, 
179-196. https://doi.org/10.1080/10413200591010021

Van Raalte, J. L., Brewer, B. W., Rivera, P. M., \& Petitpas, A. J. (1994). The Relationship between Observable Self-Talk and Competitive Junior Tennis Players' Match Performance. Journal of Sport and Exercise Psychology, 16, 400-415. https://doi.org/10.1123/jsep.16.4.400

Vealey, R. S., Armstrong, L., Comar, W., \& Greenleaf, C. A. (1998). Influence of Perceived Coaching Behaviors on Burnout and Competitive Anxiety in Female College Athletes. Journal of Applied Sport Psychology, 10, 297-318. https://doi.org/10.1080/10413209808406395

Vella, S., Oades, L. G., \& Crowe, T. P. (2010). The Application of Coach Leadership Models to Coaching Practice: Current State and Future directions. International Journal of Sports Science and Coaching, 5, 425-434. https://doi.org/10.1260/1747-9541.5.3.425

Wałach-Biśta, Z. (2013). A Polish Adaptation of Leadership Scale for Sports-A Questionnaire Examining Coaching Behavior. Human Movement, 14, 265-274. https://doi.org/10.2478/humo-2013-0032

Wandzilak, T., Ansorge, C. J., \& Potter, G. (1988). Comparison between Selected Practice and Game Behaviors of Youth Sport Soccer Coaches. Journal of Sport Behavior, 40, 78-88.

Weinberg, R. S., \& Gould, D. (2015). Foundations of Sport and Exercise Psychology (6th ed.). Human Kinetics.

Weinberg, R. S., Grove, R., \& Jackson, A. (1992). Strategies for Building Self-Efficacy in Tennis Players: A Comparative Analysis of Australian and American Coaches. The Sport Psychologist, 6, 3-13. https://doi.org/10.1123/tsp.6.1.3

Weiss, M. R., \& Friedrichs, W. D. (1986). The Influence of Leader Behaviors, Coach Attributes, and Institutional Variables on Performance and Satisfaction of Collegiate Basketball Teams. Journal of Sport Psychology, 8, 332-346. https://doi.org/10.1123/jsp.8.4.332

Williams, J., Kenow, L., Jerome, G., Rogers, T., Sartain, T. \& Darland, G. (2003). Factor Structure of the Coaching Behavior Questionnaire and Its Relationship to Athlete Variables. The Sport Psychologist, 17, 16-34. https://doi.org/10.1123/tsp.17.1.16

Zhang, J. (1993). Modification and Revision of the Leadership Scale for Sports. Unpublished Doctoral Dissertation, Springfield College.

Zhang, J., Jensen, B. E., \& Mann, B. L. (1997). Modification and Revision of the Leadership Scale for Sport. Journal of Sport Behavior, 20, 105-121.

Zourbanos, N., Theodorakis, Y., \& Hatzigeorgiadis, A. (2006). Coaches' Behavior, Social Support, and Athletes' Self-Talk. Hellenic Journal of Psychology, 3, 117-133. 